\title{
Safety and efficacy of ETC-1002 in hypercholesterolaemic patients: a meta-analysis of randomised controlled trials
}

\author{
Xiaolin Wang ${ }^{1}$, Shilan Luo ${ }^{1}$, Xiuni Gan ${ }^{2}$, Chengyu $\mathrm{He}^{2}$, Rongzhong Huang ${ }^{1}$ \\ 'Department of Geriatrics, The Second Affiliated Hospital of Chongqing Medical University, Chongqing Province, People's Republic of China \\ ${ }^{2}$ Department of Nursing, The Second Affiliated Hospital of Chongqing Medical University, Chongqing Province, People's Republic of China
}

\begin{abstract}
Background: Due to the myopathic adverse events of statins, safer alternatives are being studied. Bempedoic acid (ETC-1002) is a novel low-density lipoprotein cholesterol (LDL-C)-lowering agent, currently under trial in hypercholesterolaemic patients.

Aim: To investigate the tolerability and efficacy of ETC-1002 in hypercholesterolaemic patients through a systematic review of published randomised controlled trials (RCTs).

Methods: Five databases were searched for RCTs that investigated the safety and efficacy of ETC-1002 in hypercholesterolaemic patients. The retrieved search results were screened, and then data were extracted and analysed (as mean difference [MD] or odds ratio [OR]) using the RevMan software.

Results: Five RCTs (625 hypercholesterolaemic patients) were identified. ETC-1002 was superior to placebo in terms of percentage changes from baseline in serum levels of LDL-C (MD -26.58, 95\% confidence interval [CI] -35.50 to $-17.66, p<0.0001)$, non-high-density lipoprotein cholesterol (MD -21.54, 95\% Cl -28.48 to -14.6, $\mathrm{p}<0.00001$ ), and apolipoprotein-B (MD $-15.97,95 \% \mathrm{Cl}-19.36$ to $-12.57, \mathrm{p}<0.0001)$. When compared to ezetimibe, ETC-1002 was superior in reducing LDL-C $(-30.1 \pm 1.3$ vs. $-21.1 \pm 1.3)$. Regarding safety, ETC-1002 did not increase the risk of all adverse events $(\mathrm{OR} 0.58,95 \% \mathrm{Cl}$ $0.37-0.91, \mathrm{p}=0.02$ ) and arthralgia (OR $0.32,95 \% \mathrm{Cl} 0.13-0.81, \mathrm{p}=0.02$ ) compared to placebo. All other adverse events including myalgia, headache, and urinary tract infections were similar between ETC-1002 and placebo groups. The evidence certainty in the assessed outcomes was moderate to high except for lipoprotein(a), free fatty acids, and very low-density lipoprotein particle number (very low certainty).

Conclusions: ETC-1002 is a safe and effective lipid-lowering agent and may be a suitable alternative in statin-intolerant patients. Well-designed studies are needed to explore the long-term safety and efficacy of ETC-1002 in these patients.
\end{abstract}

Key words: bempedoic acid, dyslipidaemia, ETC-1002, hypercholesterolaemia, meta-analysis

Kardiol Pol 2019; 77, 2: 207-216

\section{INTRODUCTION}

Cardiovascular disease (CVD) remains the leading cause of death worldwide, and its prevalence is expected to rise by approximately $10 \%$ in 2030 [1, 2]. A cost prediction study by the American Heart Association (AHA) anticipated the direct medical costs (measured in 2008 dollars) of CVD to triple by 2030 [1]. Therefore, improvements in treatment and protection from the established risk factors are warranted to minimise the growing burden of CVD [1].
Statins are the standard of care for prevention of cardiovascular events, supported by a large body of evidence showing their effectiveness in reducing low-density lipoprotein cholesterol (LDL-C) levels [3]. However, statin therapy is associated with muscular adverse events in $5 \%$ to $29 \%$ of patients [4-7], referred to as statin intolerance. Although there is no universal definition of statin intolerance, muscular symptoms including pain, myalgia, and rarely life-threatening rhabdomyolysis were reported in several studies $[4,7,8]$.

\section{Address for correspondence:}

Dr. Rongzhong Huang, Department of Geriatrics, The Second Affiliated Hospital of Chongqing Medical University, Chongqing, People's Republic of China, tel: +8617823972583, e-mail: rzhuang@live.com

Received: 30.07.2018 Accepted: 17.01.2019 Available as AoP: 18.01.2019

Kardiologia Polska Copyright (C) Polish Cardiac Society 2019 
Conversely, cessation of statin therapy significantly increases the cardiovascular risk and reduces the lifespan by an average of eight years $[8,9]$. There is an imperative need for treatment alternative to statins in order to improve cardiovascular outcomes in patients with hypercholesterolaemia. This was recognised in the latest guidelines of the American College of Cardiology/AHA [10] and the European Atherosclerosis Society Consensus Panel statement on statin-associated muscle symptoms [4].

Bempedoic acid (ETC-1002, Esperion Therapeutics Inc., Ann Arbor, MI, USA) is a novel investigational drug for dyslipidaemia. It inhibits adenosine triphosphate citrate lyase (an enzyme upstream of 3-hydroxy-3-methylglutaryl-coenzyme A reductase) to reduce cholesterol biosynthesis [11, 12]. Preclinical studies have shown promising inhibitory effects on sterol and fatty acid biosynthesis. In addition, ETC-1002 could enhance fatty acid oxidation in animal models [11-14]. Supported by the favourable effects in preclinical and early phase I studies, a range of doses have been investigated in several trials that showed good tolerability for this agent with no dose-limiting adverse effects [15-18].

In this study, we aimed to systematically review the published randomised controlled trials (RCTs) on the safety and efficacy of ETC-1002 in hypercholesterolaemic patients.

\section{METHODS}

This review was conducted and reported according to the preferred reporting items for systematic reviews and meta-analyses (PRISMA) statement (Suppl. Fig. 1 - see journal website). The protocol of this study was predefined and is available as Supplementary Figure 2 (see journal website).

\section{Eligibility criteria}

We included RCTs that fulfilled the following criteria; (1) population: hypercholesterolaemic men and women aged 18 to 80 years, (2) intervention: ETC-1002 at all doses, (3) control: any other agent with head-to-head comparison, and (4) outcomes: safety and efficacy parameters related to the treatment. The primary efficacy outcomes were LDL-C, high-density lipoprotein cholesterol (HDL-C), non-HDL-C, and total cholesterol levels. The primary safety outcomes were all adverse events, serious adverse events, adverse events leading to discontinuation, headache, and myalgia. We excluded the following types of studies; (1) non-randomised trials, (2) non-English publications, and (3) theses or (4) conference papers due to inadequate data for risk of bias (ROB) assessment.

\section{Search strategy}

Five electronic databases were searched on 23 $3^{\text {rd }}$ May 2018 for relevant articles: Scopus, Cochrane Central, PubMed, Embase, and Web of Science. The following terms were used: (bempedoic acid OR ETC-1002 OR ESP55016) AND (familial hypercholesterolaemia OR hypercholesterolaemic OR hypercholesterolaemia OR high cholesterol levels OR elevated cholesterol OR hyperlipidaemia OR dyslipidaemia). We used the Medical Subject Headings database to define synonyms for the primary search terms, e.g. (ETC-1002: bempedoic acid OR ESP55016), to increase the sensitivity of our search results. Two authors independently screened the titles and abstracts of the retrieved citations and full-text evaluation was subsequently performed. Discrepancies were resolved by discussion between authors.

\section{Data extraction}

Two authors extracted the data independently using an online standardised extraction form prepared in MS Excel. The extracted data included the following: (1) characteristics of study design, (2) baseline data of enrolled patients, (3) ROB domains, and (4) study outcomes. Dichotomous data were extracted as events and total number of patients within study groups, while continuous data were extracted as means, standard deviations, and numbers of patients within study groups. Any discrepancies were discussed by the authors until consensus was reached.

\section{Quality assessment}

The ROB in the eligible studies was assessed using the Cochrane Collaboration's tool for ROB assessment in RCTs. The following domains were considered: generation of the allocation sequence, allocation concealment, blinding of participants, masking of outcome assessors, selective outcome reporting, incomplete follow-up, and other potential sources of bias. Following ROB assessment, we employed the Grading of Recommendations Assessment, Development, and Evaluation (GRADE) approach at the outcome level [19]. Based on the GRADE approach, quality of the outcome evidence in the studies was labelled as very low, low, moderate, or high. Five domains were evaluated to grade the studies: (1) ROB, (2) generalisability of results, (3) consistency of results, (4) precision of data, and (5) risk of publication bias.

The quality of evidence was specifically determined by the study design (a randomised trial was graded "high," an observational study was graded "low," and any other evidence was graded "very low"). GRADE was lower if there were serious or very serious concerns with regard to the study quality, inconsistency, uncertainty about directness, sparse/imprecise data, or reporting bias. GRADE was higher when the evidence of association was strong or very strong, evidence of dose response gradient was reported, or plausible confounders would have reduced the reported effect.

\section{Statistical analysis}

Dichotomous data were pooled as odds ratio (OR) using the Mantel-Haenszel method. Continuous data were pooled as mean difference (MD) using the inverse-variance method. The missing standard deviations were calculated from the standard error or 95\% confidence interval $(\mathrm{Cl})$ according to the Cochrane handbook for systematic review of interven- 


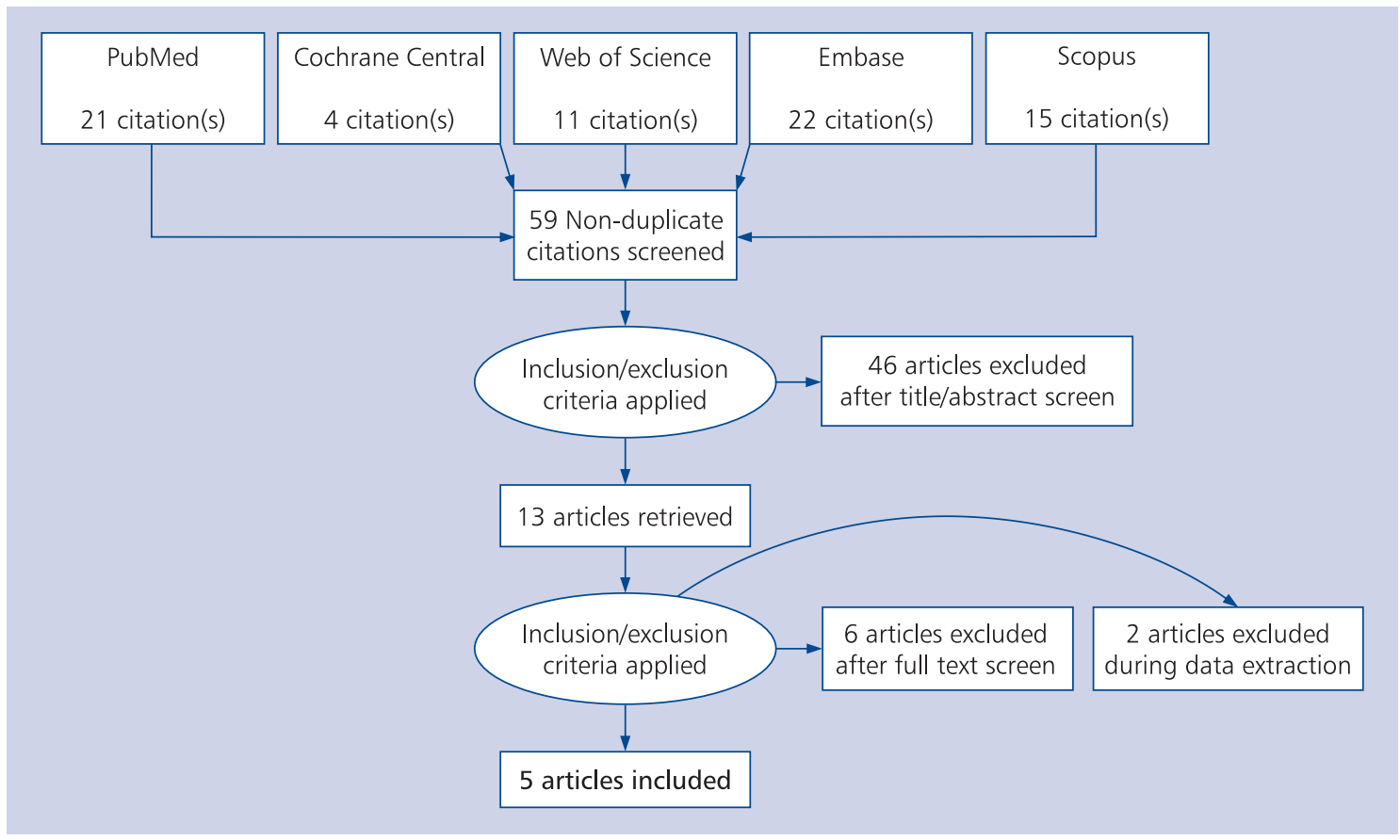

Figure 1. PRISMA flow diagram of literature search and study inclusion

tions [20]. We used the Review Manager (RevMan version 5.3 for windows) to conduct meta-analyses and generate the forest plots.

\section{Assessment of heterogeneity}

Heterogeneity was assessed by visual inspection of the forest plots and measured by I-square and $\chi^{2}$ tests. We assessed and interpreted heterogeneity according to the recommendations of the Cochrane Handbook for Systematic Reviews of Interventions (Chapter 9) [20]. When significant heterogeneity was present $\left(\chi^{2}, p<0.1\right)$, we performed the analysis under the random effects model. Otherwise, the fixed effects model was adopted. To identify the reason for the heterogeneity, we performed sensitivity analysis using the leave-one-out method.

\section{Publication bias}

According to Egger et al. [21], publication bias assessment is not reliable for less than 10 pooled studies per outcome. Therefore, in the present study, we could not assess the existence of publication bias by Egger's test for funnel plot asymmetry.

\section{RESULTS}

Summary and quality of the included studies Database searching yielded 59 unique citations. After title and abstract screening, 13 full-text articles were left for further scrutiny. Of these, five articles were eligible for our review: four of them compared ETC-1002 to placebo and were eligible for meta-analysis [15-18]. The fifth article was a phase Ilb trial that compared a range of doses of ETC-1002 to ezetimibe
(EZE) alone and their combination (Fig. 1) [22]. The list of excluded studies and reasons for exclusion are illustrated in Supplementary Figure 3 (see journal website). The summary of the included studies and the baseline characteristics of the enrolled patients are presented in Table 1.

The ROB in the included studies was assessed using the Cochrane ROB assessment tool (Suppl. Fig. 4 - see journal website). Independent evaluation of all pooled studies showed low $\mathrm{ROB}$ in terms of random sequence generation and selective outcome reporting. However, the ROB in allocation concealment was generally unclear. On the outcome level, all assessed outcomes in the included studies had a low risk of performance and detection bias. However, in two studies more than $10 \%$ of patients withdrew from the study due to adverse events, creating a high risk of attrition bias in all assessed outcomes [15, 18].

\section{Outcomes \\ Efficacy}

The overall mean difference favoured ETC-1002 over placebo in terms of percentage change from baseline in LDL-C level (MD -26.58, 95\% Cl-35.50 to -17.66, $\mathrm{p}<0.0001$, moderate certainty), non-HDL-C level (MD $-21.54,95 \% \mathrm{Cl}-28.48$ to -14.6, $\mathrm{p}<0.00001$, moderate certainty), apolipoprotein-B level (MD -15.97, 95\% Cl-19.36 to -12.57 , $\mathrm{p}<0.0001$, high certainty), LDL particle number (MD -18.75, 95\% Cl -23.26 to $-14.24, \mathrm{p}<0.0001$, moderate certainty), $\mathrm{HDL}$ particle number (MD 6.07, 95\% Cl 2.60-9.54, $p=0.0006$, moderate certainty), and total cholesterol level (MD -17.2, $95 \% \mathrm{Cl}-22.62$ to $-11.61, \mathrm{p}<0.00001$, high certainty; Fig. 2). 
Table 1. The summary of the included studies and baseline characteristics of patients

\begin{tabular}{|c|c|c|c|c|c|c|c|c|c|}
\hline $\begin{array}{l}\text { Author, } \\
\text { year }\end{array}$ & Study design & Population & Groups & $\begin{array}{c}\text { Sample } \\
\text { size }\end{array}$ & $\begin{array}{c}\text { Female } \\
\text { sex }\end{array}$ & $\begin{array}{c}\text { Age } \\
\text { [years] }\end{array}$ & $\begin{array}{c}\text { Weight } \\
\text { [kg] }\end{array}$ & $\begin{array}{c}\text { BMI } \\
{\left[\mathrm{kg} / \mathrm{m}^{2}\right]}\end{array}$ & $\begin{array}{c}\text { White/ } \\
\text { /Caucasian }\end{array}$ \\
\hline $\begin{array}{l}\text { Ballantyne } \\
\text { et al., } \\
2016 \\
{[16]}\end{array}$ & $\begin{array}{l}\text { Randomised, } \\
\text { double-blind, } \\
\text { parallel-group, } \\
\text { placebo- } \\
\text {-controlled, } \\
\text { multicentre, } \\
\text { phase llb trial }\end{array}$ & $\begin{array}{c}\text { Hypercholesterolaemic } \\
\text { men and women aged } \\
\text { 18-80 years with a BMl of } \\
18-45 \mathrm{~kg} / \mathrm{m}^{2} \text { who were on } \\
\text { stable statin therapy, fasting, } \\
\text { calculated LDL-C levels from } \\
115 \text { to } 220 \mathrm{mg} / \mathrm{dL} \text { and a fasting } \\
\text { TG level of } \leq 400 \text { mg/dL after } \\
\text { washout of lipid-modyfying } \\
\text { agents other than the statins }\end{array}$ & $\begin{array}{c}\text { ETC-1002 } 120 \mathrm{mg} \\
\text { ETC-1002 } 180 \mathrm{mg} \\
\text { Placebo }\end{array}$ & $\begin{array}{l}43 \\
45 \\
45\end{array}$ & $\begin{array}{l}26(61) \\
31(69) \\
22(49)\end{array}$ & $\begin{array}{c}59 \pm 9 \\
57 \pm 10 \\
56 \pm 10\end{array}$ & $\begin{array}{l}83 \pm 20 \\
83 \pm 19 \\
90 \pm 20\end{array}$ & $\begin{array}{l}30 \pm 6 \\
30 \pm 6 \\
31 \pm 6\end{array}$ & $\begin{array}{l}37(86) \\
37(82) \\
37(82)\end{array}$ \\
\hline $\begin{array}{l}\text { Thompson } \\
\text { et al., } \\
2016 \\
{[22]}\end{array}$ & $\begin{array}{l}\text { Phase IIb, } \\
\text { randomised, } \\
\text { double-blind, } \\
\text { active compar- } \\
\text { ator-controlled, } \\
\text { parallel-group } \\
\text { study }\end{array}$ & $\begin{array}{l}\text { Hypercholesterolaemic men and } \\
\text { women aged } 18-80 \text { years with } \\
\text { a BMI of } 18-45 \mathrm{~kg} / \mathrm{m}^{2} \text {, fasting, } \\
\text { calculated } \mathrm{LDL}-\mathrm{C} \text { values } \\
\text { between } 130 \text { and } 220 \mathrm{mg} / \mathrm{dL} \\
\text { and a fasting TG level } \\
\leq 400 \mathrm{mg} / \mathrm{dL} \text { after } \\
\text { washout of lipid-modyfying } \\
\text { drugs }\end{array}$ & $\begin{array}{c}\text { ETC-1002 } \\
120 \mathrm{mg} \\
\text { ETC-1002 } \\
180 \mathrm{mg} \\
\text { ETZ } 10 \mathrm{mg} \\
\text { ETZ } 10 \mathrm{mg}+ \\
\text { ETC-1002 } 120 \mathrm{mg} \\
\text { ETZ } 10 \mathrm{mg}+ \\
\text { ETC-1002 } 180 \mathrm{mg}\end{array}$ & $\begin{array}{l}99 \\
26\end{array}$ & $\begin{array}{l}(54) \\
(51) \\
(52) \\
(54) \\
(54)\end{array}$ & $\begin{array}{l}61 \pm 10 \\
59 \pm 9 \\
60 \pm 10 \\
59 \pm 10 \\
59 \pm 9\end{array}$ & $\begin{array}{l}87 \pm 18 \\
89 \pm 19 \\
85 \pm 17 \\
88 \pm 20 \\
83 \pm 22\end{array}$ & $\begin{array}{l}31 \pm 6 \\
31 \pm 5 \\
30 \pm 5 \\
30 \pm 5 \\
28 \pm 5\end{array}$ & $\begin{array}{l}(91) \\
(91) \\
(88) \\
(92) \\
(92)\end{array}$ \\
\hline $\begin{array}{l}\text { Thompson } \\
\text { et al., } \\
2015 \\
{[17]}\end{array}$ & $\begin{array}{l}\text { Phase II, } \\
\text { multicentre, } \\
\text { randomised, } \\
\text { double-blind, } \\
\text { placebo- } \\
\text {-controlled, } \\
\text { parallel-group } \\
\text { trial }\end{array}$ & $\begin{array}{l}\text { Men and postmenopausal or } \\
\text { surgically sterile women aged } \\
\text { 18-80 years, with hypercho- } \\
\text { lesterolaemia and a history of } \\
\text { intolerance to one or more } \\
\text { statins. Patients were required } \\
\text { to have a BMI between } \\
18 \text { and } 40 \mathrm{~kg} / \mathrm{m}^{2}\end{array}$ & $\begin{array}{c}\text { ETC-1002 } \\
60 \mathrm{mg} \\
\text { Placebo }\end{array}$ & 19 & $11(58)$ & $\begin{array}{l}64 \pm 5 \\
60 \pm 8\end{array}$ & NA & $\begin{array}{l}30 \pm 4 \\
29 \pm 5\end{array}$ & $\begin{array}{l}35(95) \\
19(100)\end{array}$ \\
\hline $\begin{array}{l}\text { Gutierrez } \\
\text { et al., } \\
2014 \\
{[18]}\end{array}$ & $\begin{array}{l}\text { Single-centre, } \\
\text { double-blind, } \\
\text { placebo-con- } \\
\text { trolled trial }\end{array}$ & $\begin{array}{l}\text { Patients with type } 2 \\
\text { diabetes mellitus and } \\
\text { elevated LDL-C level }\end{array}$ & $\begin{array}{c}\text { ETC-1002 } \\
80 \mathrm{mg} \\
\text { Placebo }\end{array}$ & $\begin{array}{l}30 \\
30\end{array}$ & $\begin{array}{l}13(43) \\
10(33)\end{array}$ & $\begin{array}{l}55.3 \pm 6.9 \\
56.0 \pm 9.9\end{array}$ & $\begin{array}{l}82.6 \pm 14.6 \\
80.3 \pm 10.0\end{array}$ & $\begin{array}{l}30.6 \pm 3.0 \\
29.2 \pm 3.0\end{array}$ & $\begin{array}{l}29(96.7) \\
28(93.3)\end{array}$ \\
\hline $\begin{array}{l}\text { Ballantyne } \\
\text { et al., } 2013 \\
{[15]}\end{array}$ & $\begin{array}{l}\text { Randomised, } \\
\text { double-blind, } \\
\text { placebo- } \\
\text {-controlled, } \\
\text { parallel-group } \\
\text { trial }\end{array}$ & $\begin{array}{l}\text { Men and naturally postmeno- } \\
\text { pausal or surgically sterile women } \\
\text { aged } 18-80 \text { years with } \\
\text { qualifying LDL-C (130- } \\
-220 \mathrm{mg} / \mathrm{dL} \text { ) and TG } \\
(<400 \mathrm{mg} / \mathrm{dL} \text { ) and a BMI } \\
\text { between } 18 \text { and } 35 \mathrm{~kg} / \mathrm{m}^{2}\end{array}$ & $\begin{array}{l}\text { ETC-1002 } \\
40 \mathrm{mg} \\
\text { ETC-1002 } \\
80 \mathrm{mg} \\
\text { ETC-1002 } \\
120 \mathrm{mg} \\
\text { Placebo }\end{array}$ & 45 & $21(48)$ & $59 \pm 9$ & $\begin{array}{l}\text { NA } \\
\text { NA }\end{array}$ & $\begin{array}{l}27 \pm 4 \\
29 \pm 4 \\
28 \pm 3\end{array}$ & NA \\
\hline
\end{tabular}

Data are shown as mean \pm standard deviation or number (percentage); BMI — body mass index; DBP — diastolic blood pressure; ETZ — ezetimibe; ETC-1002 — Education Programme Adult Treatment Panel III; SBP — systolic blood pressure; TC — total cholesterol; TG — triglycerides; VLDL — very low-density lipoprotein

On the other hand, our analysis showed no significant differences between ETC-1002 and placebo in terms of percentage changes from baseline in triglyceride levels (MD $5.23,95 \% \mathrm{Cl}-16.45$ to $27.01, \mathrm{p}=0.64$, moderate certainty), HDL-C level (MD-1.29, 95\% Cl-4.19 to 1.61, $\mathrm{p}=0.38$, high certainty), apolipoprotein-A1 level (MD 0.17, 95\% Cl-4.04 to 4.38, $p=0.94$, moderate certainty), lipoprotein(a) level
( $\mathrm{MD} 0,95 \% \mathrm{Cl}-13.74$ to $13.74, \mathrm{p}=1$, very low certainty), free fatty acids (MD $-5.0,95 \% \mathrm{Cl}-30.19$ to $20.19, \mathrm{p}=0.7$, very low certainty), and very low-density lipoprotein (VLDL) cholesterol particle number (MD $-10.27,95 \% \mathrm{Cl}-31.40$ to 10.86, $p=0.34$, very low certainty) (Fig. 3). The reasons for the downgrading of evidence quality in the last three parameters included imprecision and uncertainty about directness. 


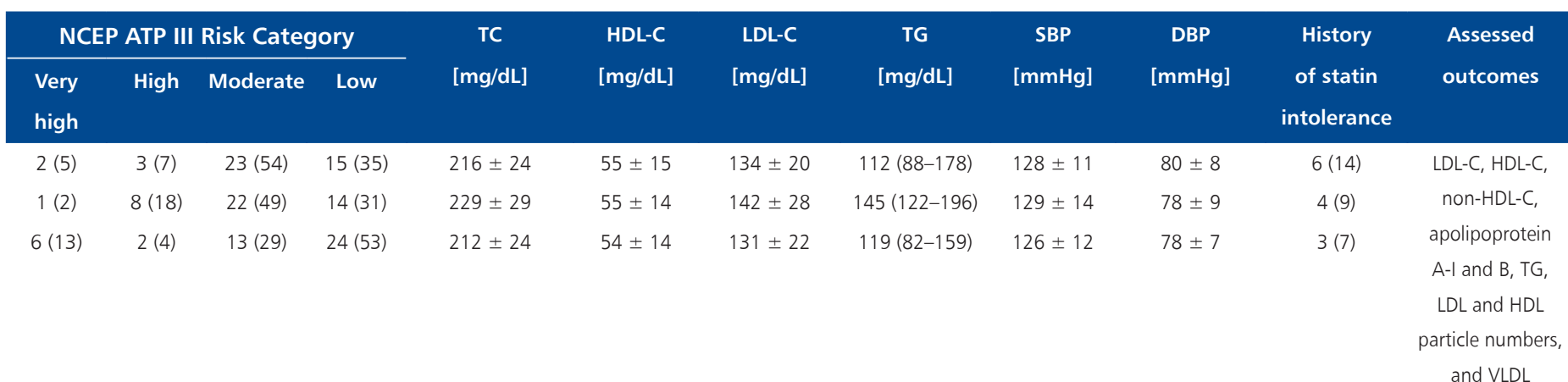

\begin{tabular}{|c|c|c|c|c|c|c|c|c|c|c|c|}
\hline$(11)$ & (14) & (38) & (36) & $249 \pm 31$ & $54 \pm 16$ & $164 \pm 28$ & $136(71,375)$ & $126 \pm 11$ & $77 \pm 8$ & $177(50.8)$ & $\begin{array}{c}\text { LDL-C, HDL-C, } \\
\text { non-HDL-C, }\end{array}$ \\
\hline (7) & $(10)$ & (49) & (34) & $253 \pm 33$ & $52 \pm 13$ & $166 \pm 24$ & $162(38,371)$ & $125 \pm 12$ & $78 \pm 7$ & & $\begin{array}{c}\text { apolipoprotein } \\
\text { A-l and B, TG, LDL }\end{array}$ \\
\hline (8) & (12) & (42) & (39) & $247 \pm 35$ & $51 \pm 15$ & $162 \pm 26$ & $161(81,332)$ & $126 \pm 11$ & $77 \pm 7$ & & $\begin{array}{l}\text { numbers, } \\
\text { and VLDL }\end{array}$ \\
\hline $4(11)$ & $4(11)$ & $27(73)$ & $2(5)$ & $263 \pm 45$ & $51 \pm 14$ & $176 \pm 37$ & $200 \pm 172$ & NA & NA & $37(100)$ & $\begin{array}{l}\text { LDL-C, HDL-C, } \\
\text { non-HDL-C, TC, }\end{array}$ \\
\hline $2(11)$ & $1(5)$ & $13(68)$ & $3(16)$ & $276 \pm 43$ & $58 \pm 18$ & $185 \pm 33$ & $166 \pm 72$ & NA & NA & $18(95)$ & $\begin{array}{l}\text { apolipoprotein } \\
\text { A1 and B, TG }\end{array}$ \\
\hline NA & NA & NA & NA & $206.3 \pm 36.1$ & $43.7 \pm 10.1$ & $125.2 \pm 27.5$ & $\begin{array}{c}181.5 \\
(86,572)\end{array}$ & $117.0 \pm 9.6$ & $76.9 \pm 5.8$ & NA & $\begin{array}{c}\text { LDL-C, HDL-C, } \\
\text { non-HDL-C, }\end{array}$ \\
\hline NA & NA & NA & NA & $206.7 \pm 34.1$ & $47.4 \pm 11.8$ & $128.4 \pm 28.5$ & $\begin{array}{c}152.0 \\
(81,248)\end{array}$ & $119.7 \pm 13.1$ & $77.5 \pm 5.9$ & NA & $\mathrm{TC}$, and $\mathrm{TG}$ \\
\hline NA & NA & NA & NA & $249 \pm 33$ & $57 \pm 14$ & $163 \pm 25$ & $148 \pm 66$ & $119 \pm 11$ & $73 \pm 8$ & NA & $\begin{array}{l}\text { LDL-C, HDL-C, } \\
\text { non-HDL-C, TC, }\end{array}$ \\
\hline NA & NA & NA & NA & $252 \pm 31$ & $50 \pm 12$ & $170 \pm 26$ & $158 \pm 68$ & $121 \pm 9$ & $78 \pm 6$ & NA & $\begin{array}{l}\text { apolipoprotein } \\
\text { A1 and B, TG }\end{array}$ \\
\hline NA & NA & NA & NA & $248 \pm 25$ & $51 \pm 12$ & $165 \pm 23$ & $159 \pm 74$ & $119 \pm 9$ & $76 \pm 6$ & NA & \\
\hline NA & NA & NA & NA & $250 \pm 26$ & $49 \pm 11$ & $167 \pm 22$ & $168 \pm 79$ & $123 \pm 9$ & $78 \pm 7$ & NA & \\
\hline
\end{tabular}

bempedoic acid; HDL-C — high-density lipoprotein-cholesterol; LDL-C — low-density lipoprotein-cholesterol; NA — not applicable; NCEP ATP III — National Cholesterol cholesterol. Conversion factors to SI units: are as fallows: for TC, LDL-C, and HDL-C (in mg/dL) - 0.02586; for TG (in mg/dL) - 0.01129.

Significant heterogeneity was observed in only four outcomes (LDL-C, non-HDL-C, total cholesterol, and triglyceride levels), and their analysis was conducted under the random effects model. Sensitivity analysis was possible in the first three outcomes in which heterogeneity was best resolved by removing the study by Gutierrez et al. 2014 [18], and the effect estimate remained significant in all four outcomes.

\section{Safety}

ETC-1002 did not increase the risk of all adverse events (OR $0.58,95 \% \mathrm{Cl} 0.37-0.91, \mathrm{p}=0.02$ ) or arthralgia (OR 0.32, $95 \% \mathrm{Cl} 0.13-0.81, \mathrm{p}=0.02)$ compared to placebo. Furthermore, we found no significant differences between both groups in the rate of serious adverse events (OR $0.35,95 \% \mathrm{Cl}$ $0.08-1.55, p=0.17)$, treatment-related adverse events (OR 


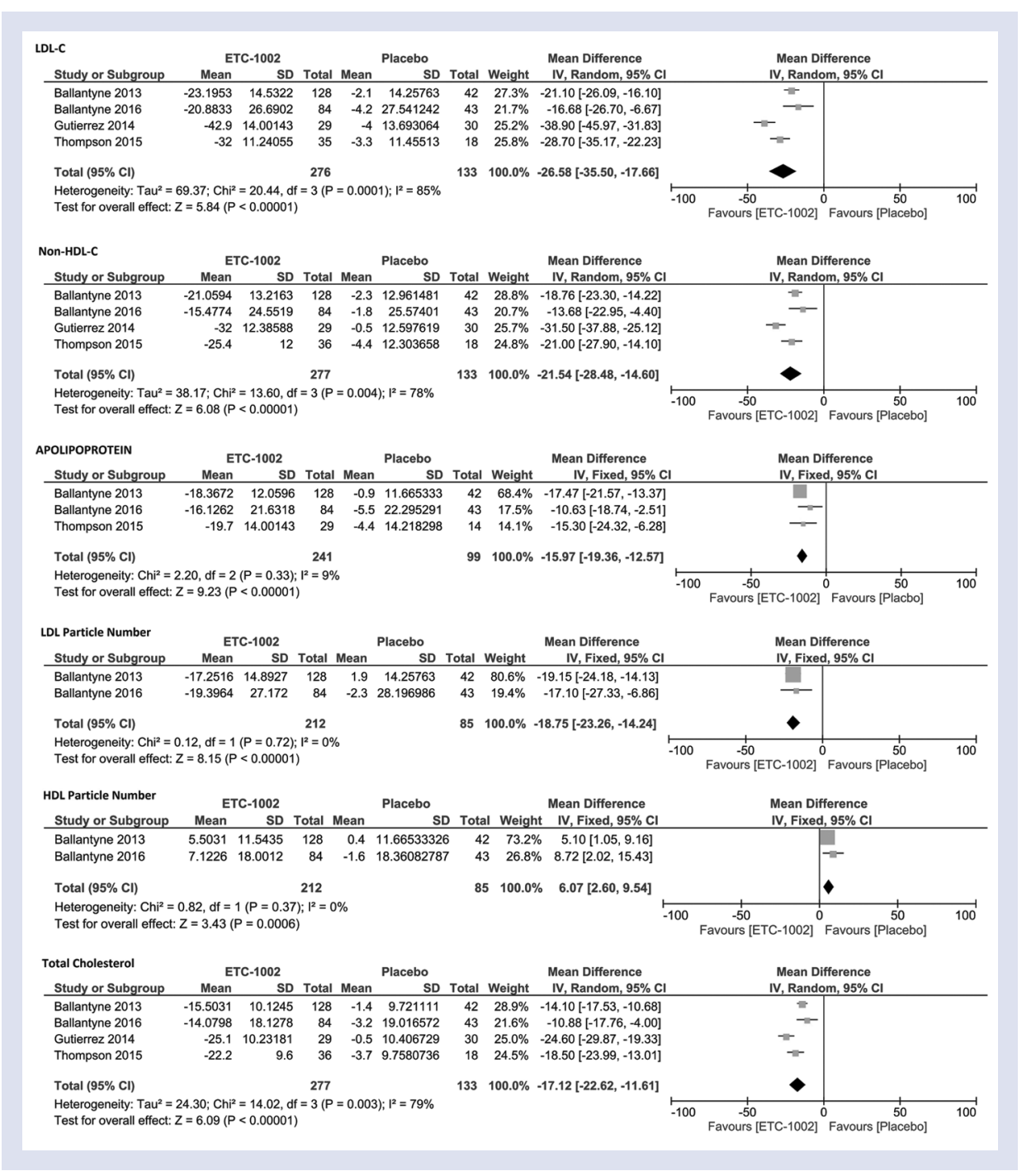

Figure 2. Forest plots of the comparison between ETC-1002 and placebo in terms of mean differences in low-density lipoprotein cholesterol (LDL-C), non-high-density lipoprotein cholesterol (non-HDL-C), apolipoprotein-B, LDL particle number, HDL particle number, and total cholesterol

$0.76,95 \% \mathrm{Cl} 0.43-1.34, \mathrm{p}=0.34)$, adverse events leading to discontinuation (OR $0.57,95 \% \mathrm{Cl} 0.23-1.46, \mathrm{p}=0.24$ ), headache (OR 1.36, 95\% Cl 0.63-2.96, $\mathrm{p}=0.43)$, urinary tract infection (OR 1.77, 95\% Cl 0.53-5.87, $\mathrm{p}=0.35)$, and myalgia (OR 1.09, 95\% Cl 0.30-3.89, p =0.9) (Fig. 4). All analyses of adverse effects had high certainty except for serious adverse events and adverse events leading to discontinuation (moderate certainty).

In a phase IIb randomised controlled trial [22], Thompson et al. [22] showed that ETC-1002 alone is more effective than EZE alone in reducing LDL-C levels. Both $120 \mathrm{mg}$ and $180 \mathrm{mg}$ doses of ETC-1002 were superior to EZE $10 \mathrm{mg}$ dose in reducing LDL-C levels $(-27.5 \pm 1.3$ vs. $-30.1 \pm 1.3$ vs. $-21.1 \pm 1.3$ for ETC-1002 120 mg, ETC-1002 180 mg and EZE 10 mg, respectively). The combination of ETC-1002 and EZE was much more effective $(-43.1 \pm 2.6$ vs. $-47.7 \pm 2.8$ vs. $-21.1 \pm 1.3$ for ETC-1002 $120 \mathrm{mg}$ plus EZE $10 \mathrm{mg}$, ETC-1002 $180 \mathrm{mg}$ plus EZE $10 \mathrm{mg}$, and EZE $10 \mathrm{mg}$ monotherapy, respectively). The analysis of LDL particle number, apolipoprotein-B, total cholesterol, non-HDL-C, and triglycerides levels favoured both ETC-1002 monotherapy and ETC-1002 plus EZE combination over EZE alone.

\section{DISCUSSION}

In this systematic review and meta-analysis, we investigated the safety and efficacy of ETC-1002, a novel LDL-C lowering agent. A total of 625 hypercholesterolaemic patients were classified into either the ETC-1002 group (487 patients) or the placebo group (138 patients). Analysis of data extracted from four studies [15-18] showed that the overall MD of decreasing LDL-C, non-HDL-C, apolipoprotein-B, and total cholesterol levels as well as LDL particle number favoured 


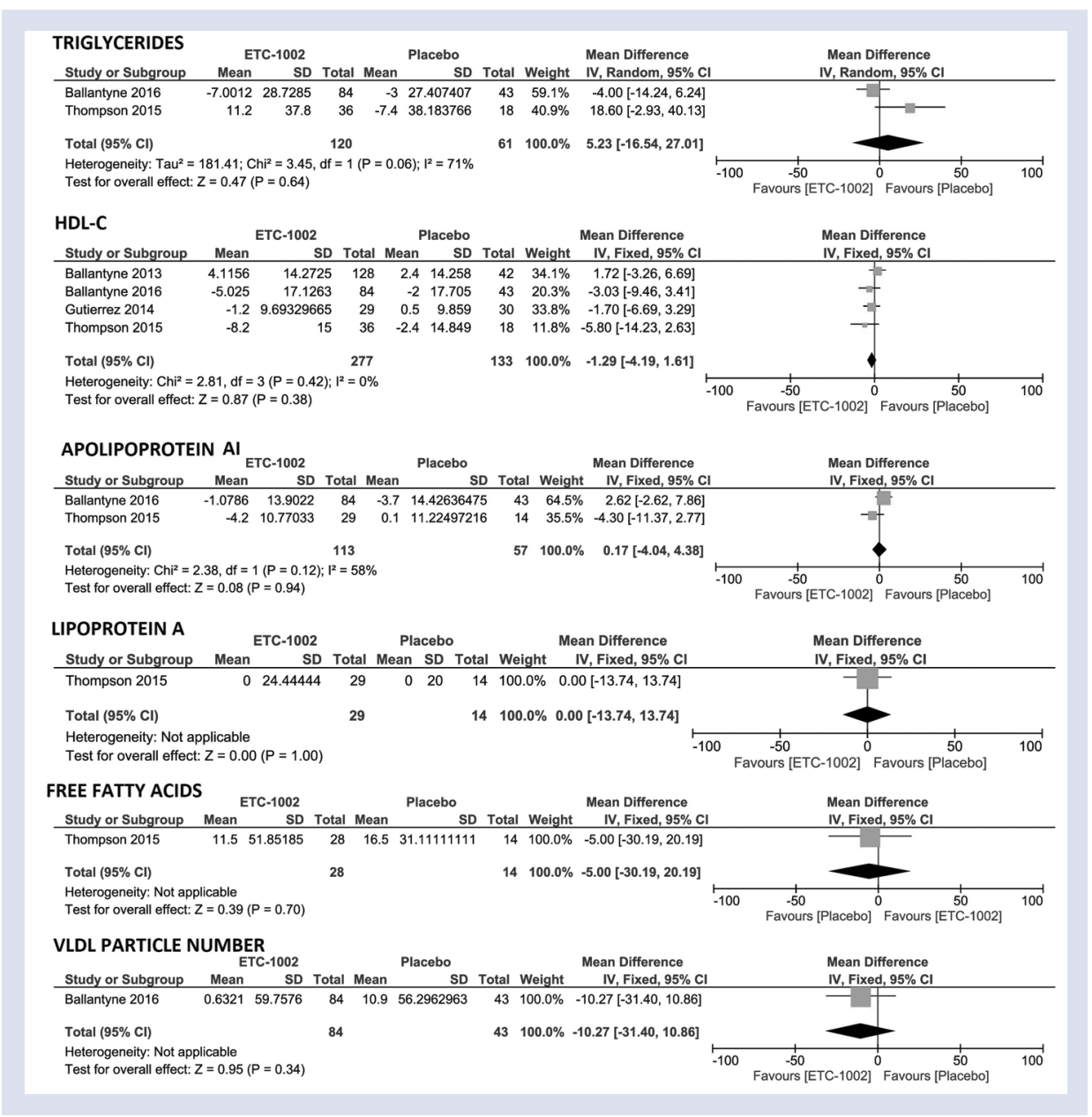

Figure 3. Forest plots of the comparison between ETC-1002 and placebo in terms of mean differences in triglycerides, high-density lipoprotein cholesterol (HDL-C), apolipoprotein-A1, lipoprotein(a), free fatty acids, and very low-density lipoprotein (VLDL) cholesterol particle number

ETC-1002 over placebo. With regard to safety, there was no significant difference between placebo and ETC-1002 in terms of serious adverse events, treatment-related events, adverse events that led to discontinuation, headache, urinary tract infection, or myalgia.

Two studies included patients who were statin-intolerant due to muscular adverse events $[17,22]$. In the study of Thompson et al. [22], the investigators compared two doses of ETC-1002 (120 and $180 \mathrm{mg}$ ) alone or combined with EZE 10 mg vs. EZE monotherapy in patients with hypercholesterolaemia for lowering of LDL-C levels. It was the first study to compare ETC-1002 and other statin-alternative medications. The authors concluded that ETC-1002 with or without EZE may be useful and effective in patients with hypercholesterolaemia. Therefore, ETC-1002 may be useful for patients who are unable to tolerate statins because of muscle side effects.

Significant statistical heterogeneity was recorded in four outcomes (LDL-C, non-HDL-C, total cholesterol, and triglyceride levels) and it was resolved upon excluding the study by
Gutierrez et al. [18]. A possible reason for the heterogeneity caused by including this study in the analysis was the difference in baseline variables of the patients, compared to other studies. For example, this study only included diabetic patients, and the mean baseline total cholesterol, LDL-C, and HDL-C values in these patients were markedly lower than in their counterparts included in other studies.

A pharmacokinetics study of ETC-1002 showed that this agent is rapidly absorbed from the small intestine. Moreover, it has cell surface receptors through which it enters the liver [23]. Chemically, ETC-1002 is a dicarboxylic acid derivative. It has two mechanisms of action: it inhibits hepatic ATP citrate lyase $(\mathrm{ACL})$ and activates adenosine monophosphate-activated protein kinase (AMPK) [14]. Through these mechanisms, ETC-1002 exerts its effects on fatty acid and cholesterol metabolism. ETC-1002 rapidly reduces acetyl coenzyme A (CoA) levels and induces the uptake of LDL particles by the liver, which leads to reduced blood LDL-C levels [23].

ETC-1002 has the potential to regulate metabolic imbalance in both the lipid and carbohydrate metabolic path- 


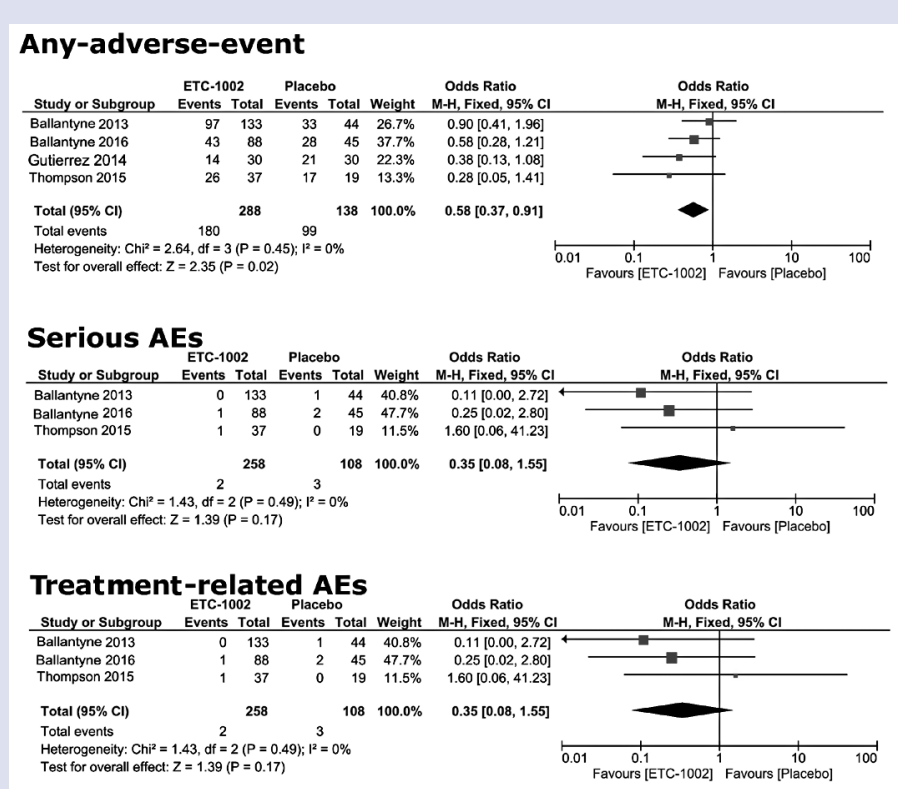

\section{AEs leading to discontinuation}
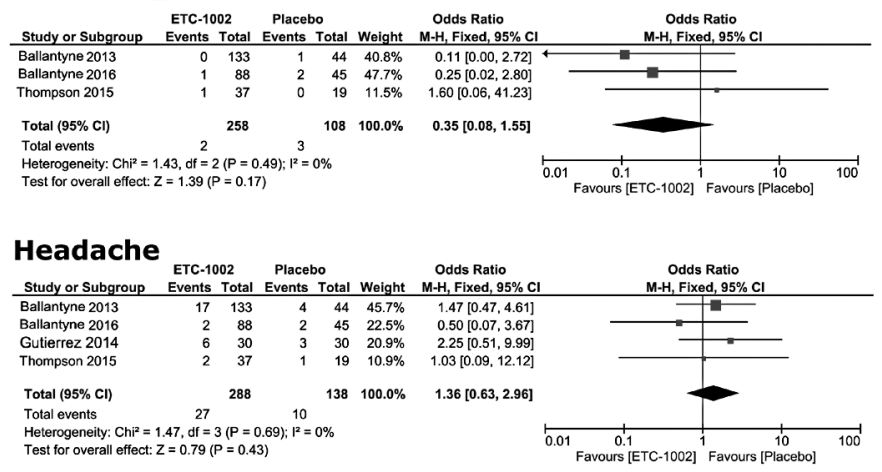

UTI

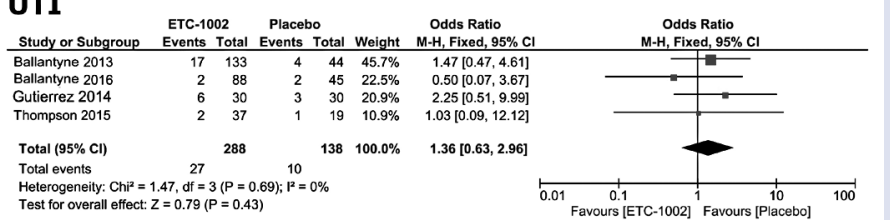

Myalgia

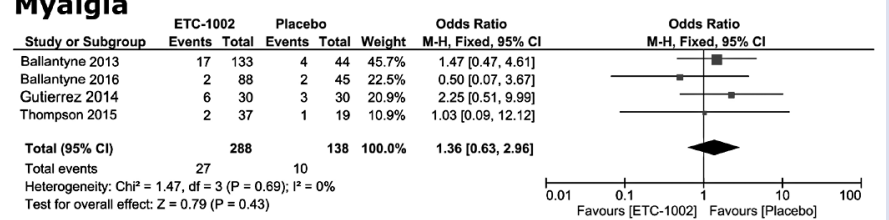

\section{Arthralgia}

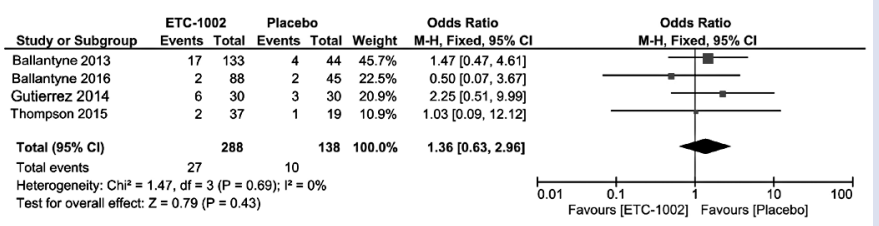

Figure 4. Forest plots of the comparison between ETC-1002 and placebo in terms of odds ratio of all adverse events, serious adverse events (AEs), treatment-related AEs, AEs that led to discontinuation, headache, urinary tract infection (UTI), myalgia, and arthralgia 
ways. In addition, it inhibits sterol and fatty acid synthesis, increases mitochondrial long-chain fatty acid oxidation, and improves glucose metabolism [24]. Because ETC-1002 targets different enzymes in the cholesterol synthesis cascade, the end result is overall reduction in cholesterol synthesis. The decreased cholesterol synthesis leads to upregulation of LDL receptors and subsequent reduction in the circulating levels of LDL-C (which is similar to the mechanism of statins). On the other hand, activation of AMPK leads to inhibitory phosphorylation of acetyl-CoA carboxylase and HMG-CoA reductase, which in turn leads to decreased blood glucose, lipid, and body weight [23].

\section{Strengths and limitations}

In this study, we performed a comprehensive search of five major databases to retrieve all relevant studies. The low risk of bias in most domains on the Cochrane ROB tool adds to the strength of our findings. We also performed a GRADE assessment to evaluate the certainty of evidence. This assessment showed an acceptable level of reliability for our findings because most outcomes had good levels of certainty (ranging from moderate to high). However, in three outcomes, the evidence certainty was very low (lipoprotein[a], free fatty acids, and VLDL cholesterol particle number), and the reasons for evidence certainty downgrade included imprecision and uncertainty about directness. Future studies should focus on these parameters.

One of the limitations of our study was the difference in baseline characteristics of the patients included in the studies (age, diabetes, and other cardiovascular risk factors). Moreover, the included studies used different doses and durations of treatment with ETC-1002 (doses ranged from 40 to $240 \mathrm{mg}$ and duration of therapy ranged from six to 12 weeks). The 80 and $120 \mathrm{mg}$ doses were investigated in most of the studies; therefore, they are better candidates for future research. Ballantyne et al. [15] administered ETC-1002 at 40, 80, and $120 \mathrm{mg}$ for 12 weeks, while Ballantyne et al. [16] used ETC-1002 120 and $180 \mathrm{mg}$ for the same period. Thompson et al. [17] started with ETC-1002 at $60 \mathrm{mg}$ then increased the dose to 120,180 , and $240 \mathrm{mg}$ for eight weeks, while in a study by Thompson et al. [22], patients were randomised to 12-week treatment with ETC-1002 120 or 180 mg. Additionally, our search was limited to articles published in English, therefore, owing to the small number of included studies, we could not assess the risk of publication bias. Another common limitation related to the meta-analysis design of the study is that the results are limited by the data presented in the included studies. Therefore, in this study, we could not analyse the impact of ETC-1002 on clinically relevant outcomes such as blood pressure or ischaemic manifestations.

\section{Future research recommendations}

Future studies should directly compare ETC-1002 to statins in terms of efficacy to prove non-inferiority. The impact of ETC-
1002 treatment on clinical outcomes and complications of hypercholesterolaemia, such as coronary and peripheral artery disease, should be investigated in future trials. Moreover, basic scientific and translational research should be encouraged to identify new targets of cholesterol-lowering therapy and develop more drugs from phytochemical and pharmaceutical agents $[25,26]$.

In conclusion, ETC-1002 is a safe and effective lipid-lowering agent in hypercholesterolaemic patients and may be a good treatment alternative for patients with statin intolerance. Moreover, the combination of ETC-1002 and EZE could offer better lipid-lowering effects than EZE alone. Except for a few outcomes that should be further investigated (such as free fatty acids and VLDL cholesterol particle number), the evidence certainty for most of the analysed results was moderate to high. Future studies should make head-to-head comparisons between ETC-1002 and statins and investigate the benefits of replacing or supplementing statins with ETC-1002.

\section{Acknowledgements}

This work was supported by the National Nature Science Foundation for the Youth of China (grant No. 81202005, to X.W.), the Technology Plan Fund of Hunan Science (grant No. 2013FJ4109, to X.W.), and the Central South University Innovation Fund for Independent Graduate Exploration (grant No. 72150050587 , to X.W.).

\section{Conflict of interest: None to declared}

\section{References}

1. Heidenreich P, Trogdon J, Khavjou O, et al. Forecasting the Future of Cardiovascular Disease in the United States. Circulation. 2011; 123(8): 933-944, doi: 10.1161/cir.0b013e31820a55f5.

2. Roger VL. Heart Disease and Stroke Statistics-2012 Update: A Report From the American Heart Association (vol 125, pg e2, 2012). Circulation. 2012; 125(22): E1002-E1002.

3. Waters DD. What the statin trials have taught us. Am J Cardiol. 2006; 98(1): 129-134, doi: 10.1016/j.amjcard.2006.01.066, indexed in Pubmed: 16784935.

4. Stroes ES, Thompson PD, Corsini A, et al. European Atherosclerosis Society Consensus Panel. Statin-associated muscle symptoms: impact on statin therapy: European Atherosclerosis Society Consensus Panel Statement on Assessment, Aetiology and Management. Eur Heart J. 2015; 36(17): 1012-1022, doi: 10.1093/eurhearti/ehv043, indexed in Pubmed: 25694464.

5. Parker BA. Effect of Statins on Skeletal Muscle: Exercise, Myopathy, and Muscle Outcomes (vol 40, pg 188, 2012). Exerc Sport Sci Rev. 2013; 41(1): 71-71

6. Ito MK, Maki KC, Brinton EA, et al. Muscle symptoms in statin users, associations with cytochrome P450, and membrane transporter inhibitor use: a subanalysis of the USAGE study. J Clin Lipidol. 2014; 8(1): 69-76, doi: 10.1016/j.jacl.2013.10.006, indexed in Pubmed: 24528687.

7. Guyton JR, Bays HE, Grundy SM, et al. An assessment by the Statin Intolerance Panel: 2014 update. J Clin Lipidol. 2014; 8(3 Suppl): S72-S81, doi: 10.1016/j.jacl.2014.03.002, indexed in Pubmed: 24793444.

8. Mampuya WM, Frid D, Rocco M, et al. Treatment strategies in patients with statin intolerance: the Cleveland Clinic ex- 
perience. Am Heart J. 2013; 166(3): 597-603, doi: 10.1016/j. ahj.2013.06.004, indexed in Pubmed: 24016512.

9. Simpson RJ, Mendys P. The effects of adherence and persistence on clinical outcomes in patients treated with statins: a systematic review. J Clin Lipidol. 2010; 4(6): 462-471, doi: 10.1016/j. jacl.2010.08.026, indexed in Pubmed: 21122692.

10. Stone NJ, Robinson JG, Lichtenstein AH, et al. 2013 ACC/AHA guideline on the treatment of blood cholesterol to reduce atherosclerotic cardiovascular risk in adults: a report of the American College of Cardiology/American Heart Association Task Force on Practice Guidelines. J Am Coll Cardiol. 2014; 63(25 Part B): 2889-2934.

11. Cramer CT, Goetz B, Hopson KLM, et al. Effects of a novel dual lipid synthesis inhibitor and its potential utility in treating dyslipidemia and metabolic syndrome. J Lipid Res. 2004; 45(7): 1289-1301, doi: 10.1194/jlr.M400018-JLR200, indexed in Pubmed: 15102884.

12. Srivastava R, Hurley TR, Brant AF, et al. A novel small molecule, ETC-1002, lowers proatherogenic lipoproteins, reduces adiposity, and improves hepatic steatosis in a hyperlipidemic hamster model. Orlando, FL: Am Heart Assoc Scientific Sessions. 2011 Abstract. 25085

13. Hanselman J, Bradshaw C, Brant A, et al. ETC-1002 reduces circulating and hepatic triglyceride content and improves glycemic control in KKAy mice. Chicago, IL: Am Heart Assoc; Arteriosclerosis, Thrombosis and Vascular Biology Scientific Sessions. 2011 Abstract. 657.

14. Pinkosky SL, Filippov S, Srivastava RA, et al. AMP-activated protein kinase and ATP-citrate lyase are two distinct molecular targets for ETC-1002, a novel small molecule regulator of lipid and carbohydrate metabolism. J Lipid Res. 2013; 54(1): 134-151, doi: 10.1194/jlr.M030528, indexed in Pubmed: 23118444.

15. Ballantyne CM, Davidson MH, Macdougall DE, et al. Efficacy and safety of a novel dual modulator of adenosine triphosphate-citrate lyase and adenosine monophosphate-activated protein kinase in patients with hypercholesterolemia: results of a multicenter, randomized, double-blind, placebo-controlled, parallel-group trial. J Am Coll Cardiol. 2013; 62(13): 1154-1162, doi: 10.1016/j. jacc.2013.05.050, indexed in Pubmed: 23770179.

16. Ballantyne CM, McKenney JM, MacDougall DE, et al. Effect of ETC-1002 on serum low-density lipoprotein cholesterol in hypercholesterolemic patients receiving statin therapy. Am J Cardiol.
2016; 117(12): 1928-1933, doi: 10.1016/j.amjcard.2016.03.043, indexed in Pubmed: 27138185.

17. Thompson PD, Rubino J, Janik MJ, et al. Use of ETC-1002 to treat hypercholesterolemia in patients with statin intolerance. J Clin Lipidol. 2015; 9(3): 295-304, doi: 10.1016/j.jacl.2015.03.003, indexed in Pubmed: 26073387.

18. GutierrezMJ, RosenbergNL,MacdougallDE, etal.Efficacyand safety ofETC-1002,anovelinvestigationallow-densitylipoprotein-cholesterol-lowering therapy for the treatment of patients with hypercholesterolemia and type 2 diabetes mellitus. Arterioscler Thromb Vasc Biol. 2014; 34(3): 676-683, doi: 10.1161/ATVBAHA.113.302677, indexed in Pubmed: 24385236.

19. Atkins D, Best D, Briss PA, et al. Grading quality of evidence and strength of recommendations. BMJ. 2004; 328(7454): 1490, doi: 10.1136/bmj.328.7454.1490, indexed in Pubmed: 15205295.

20. Higgins JP, Green S. Cochrane handbook for systematic reviews of interventions. Vol 4: John Wiley \& Sons. 2011.

21. Egger M, Davey Smith G, Schneider M, et al. Bias in meta-analysis detected by a simple, graphical test. BMJ. 1997; 315(7109): 629-634, indexed in Pubmed: 9310563.

22. Thompson P, MacDougall D, Newton R, et al. Treatment with ETC-1002 alone and in combination with ezetimibe lowers LDL cholesterol in hypercholesterolemic patients with or without statin intolerance. J Clin Lipidol. 2016; 10(3): 556-567, doi: 10.1016/j.jacl.2015.12.025.

23. Nikolic D, Mikhailidis DP, Davidson MH, et al. ETC-1002: a future option for lipid disorders? Atherosclerosis. 2014; 237(2): 705-710, doi: 10.1016/j.atherosclerosis.2014.10.099, indexed in Pubmed: 25463109.

24. GoldbergR. Targetinglow-density lipoprotein and dysmetabolism in type 2 diabetes mellitus. Arterioscler Thromb Vasc Biol. 2014;34(3): 477-478, doi: 10.1161/ATVBAHA.114.303171, indexed in Pubmed: 24554605.

25. Abdel-Daim MM, Shaheen HM, Abushouk AI, et al. Thymoquinone and diallyl sulfide protect against fipronil-induced oxidative injury in rats. Environ Sci Pollut Res Int. 2018 [Epub ahead of print], doi: 10.1007/s11356-018-2386-3, indexed in Pubmed: 29881965.

26. Nishi H, Fisher EA. Cholesterol homeostasis regulation by miR-223: basic science mechanisms and translational implications. Circ Res. 2015; 116(7): 1112-1114, doi: 10.1161/CIRCRESAHA.115.305467, indexed in Pubmed: 25814681.

Cite this article as: Wang X, Luo S, Gan X, et al. Safety and efficacy of ETC-1002 in hypercholesterolaemic patients: a meta-analysis of randomised controlled trials. Kardiol Pol. 2019; 77(2): 207-216, doi: 10.5603/KP.a2019.0013.

\section{WHAT IS NEW?}

Statins are the current gold standard in the treatment for hypercholesterolaemia. However, owing to their myopathic adverse effects, safer alternatives are being investigated. Bempedoic acid (ETC-1002) is a novel low-density lipoprotein cholesterol (LDL-C)-lowering agent, currently under trial in hypercholesterolaemic patients. Using statistical pooling of randomised controlled trials, we summarised the safety and efficacy outcomes of ETC-1002 use in these patients. ETC-1002 was effective in improving the levels of LDL-C, non-high-density lipoprotein cholesterol, and apolipoprotein-B as compared to placebo. When compared to ezetimibe, ETC-1002 was superior in reducing LDL-C levels. Moreover, ETC-1002 was not associated with increased risk of all adverse events, including arthralgia, myalgia, headache, and urinary tract infections, compared to placebo. In summary, ETC-1002 is a safe and effective cholesterol-lowering agent and may be a suitable alternative in statin-intolerant patients. 